\title{
Childcare Policy in Korea: Current Status and Major Issues
}

\author{
Ock Rhee \\ Korea Institute of Child Care and Education / Duksung Women's University \\ Korea
}

\begin{abstract}
This paper discusses the main policies and efforts aimed at childcare support undertaken by the Korean Government from 2003 to 2007, as well as dealing with the ensuing policy issues which arose as a result of such efforts. This paper also seeks to review the details and implications of the First and Second Policy Scheme of National Childcare Support, as well as those of the Nationwide Survey of Childcare and Early Childhood Education prepared by the Presidential Committee in 2004 and 2005. In addition, this study investigates changes made to major childcare support policy indicators, which can be said to be the output of implementing policy tasks. Some quantitative indicators such as the supply of childcare facilities and childcare budgets indicate clear increases while other indicators, such as teachers' salaries, the safety condition of facilities, and the actual measurements of the quality of childcare service do not indicate an increase. This paper also discusses some issues of controversy regarding childcare support policies which the government will encounter in the process of policy creation as well as actually undertaking policy projects. These issues include the expansion of public services as opposed to the utilization of private services, support for low-income families as opposed to general support, control of rather than self-regulation of childcare fees, support for institutions as opposed to direct assistance to young children, and maximization rather than the minimization of governmental intervention. This study concludes that Korea's childcare policies are evolving from a conservative approach to a more progressive one. National welfare and associated policies are expected to continue to move towards a more progressive perspective, despite the diversity of opinion within Korean society over these issues, as evidenced in current debates. This is because general financial support has been greatly increased on an annual basis and this has taken place against the backdrop of a national consensus which has seen a broadening of governmental support for childcare due to the crisis of an ever lowering fertility rate.
\end{abstract}

Key Words : Korean childcare policy, childcare support budget, Korean early childhood education policy, quality of childcare

\section{Introduction}

According to future estimates of the Korean population, based on continuing low birth rates, the population is expected to continue to decline after

Ock Rhee, President of Korea Institute of Child Care and Education, Angukbuilding 11F, 175-87 Anguk-Dong, JongnoGu, Seoul 110-734, Korea. ocrhee@kicce.re.kr peaking at 49,900,000 in 2020. The Korean Government estimates that the population figure by 2050 will have declined to $42,300,000$. In addition, it is expected that it will take a mere 18 years for Korea to evolve from an aging society, where senior citizens aged over 65 account for 7 percent of the total population, to an aged society, in which senior citizens aged over 65 account for 14 percent of the total population. From this point, it is estimated that it will only take a further 8 years for Korea 


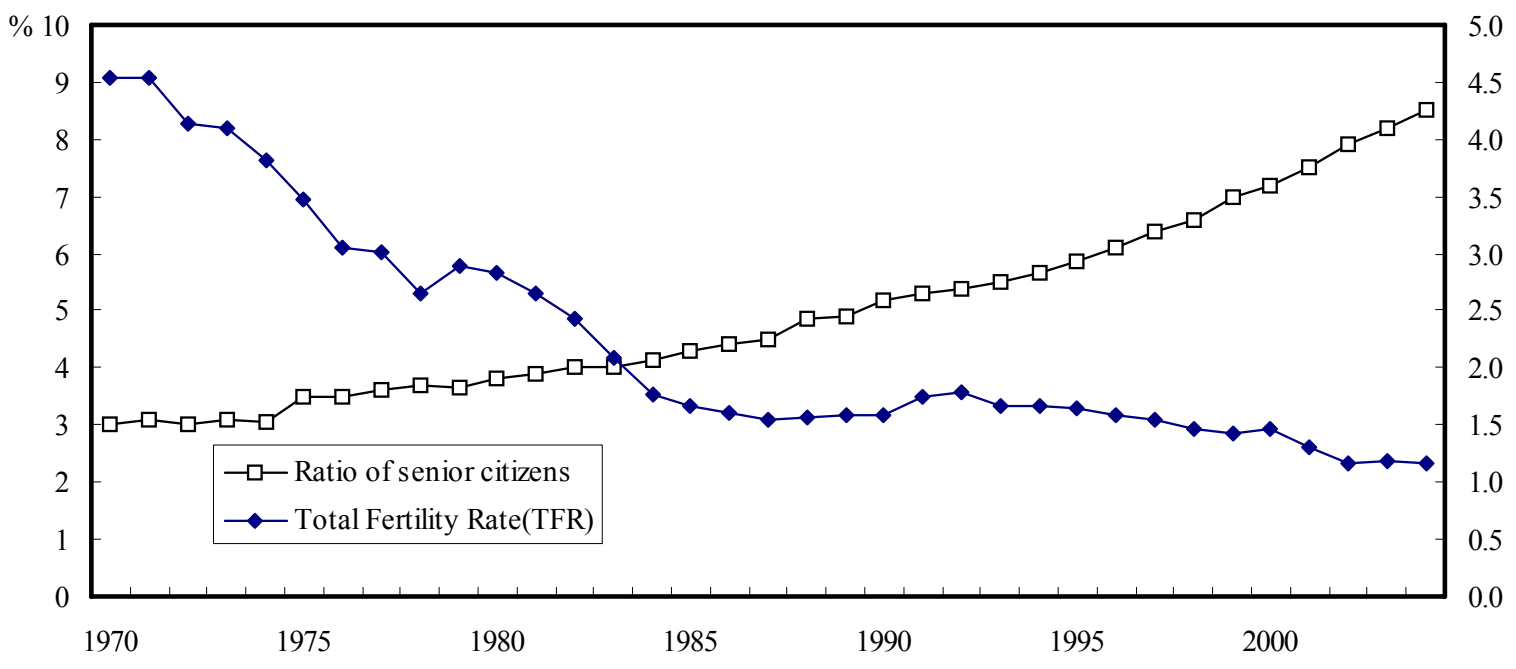

Figure 1. Relation between fertility rate and population aging ${ }^{1}$

to be a super-aged society, where aged citizens account for 20 percent of the total population. This indicates that Korean society is aging at a much faster rate when compared to other advanced nations.

As is well known, the Korean Government first implemented a strict population control policy (family planning program) in the 1960s. From the onset of this policy, the birth rate declined drastically, with the result being that Korea became an aging society in the year 2000. When advanced nations, having experienced such problems as low or declining birth rates and an increasingly aging society, saw their total fertility rates (TFR) reached 2.0, those countries established and implemented policies to increase birth rates. Since Korea's TFR has continued to decrease below 2.0 since reaching the 2.08 mark in $1983^{2}$, the Government should have recognized the serious risk of a low birth rate and should have drawn up measures to cope with it at a governmental level. With the coming to power of a new government in 2003, Korea finally began to tackle the issues and implications of a low birth rate and an aging society, by making such issues a part of the national agenda.

Childcare policies in Korea have drawn a great deal of attention ever since the first Government legislated on early childhood education and childcare. Facing a low birth rate and an aging society, the Korean Government prioritized childcare policy as a national task, set directions and objectives of a childcare support policy, and put forward detailed policy schemes.

This paper will discuss childcare support policies and the major issues related to such policies during the period from 2003 to 2007. In particular, the first part of the paper will critically review the efforts made by the Korean government since 2004, in establishing the direction for childcare policies and objectives, and choosing core policy tasks. In addition, the paper will examine changes made to major policy indicators, which can be said to be the results of policies implemented. This paper will also discuss the major issues in childcare policies which the government has had to encounter while in the process of creating and actually undertaking childcare policy projects.

\section{The Direction and Objectives of Childcare Support Policies}

\section{First Scheme of National Childcare Support Policy}

In June 2004, the First Scheme of the National Childcare Support Policy, prepared by the Presidential 
Committee on Aging and Future Society, was reported at the 46th Session of the National Agenda Meeting of Chungwadae. According to this report, the Committee expressed the need for active participation in the development of future human resources by the provision of general childcare support programs for young children. This would be done through a comprehensive approach to early childhood education and childcare, through the stating of recommendations and suggestions made by a number of ministries (Ministry of Education, Human Resources Development, Ministry of Gender Equity and Family, Ministry of Labor, \& Ministry of Agriculture and Forestry). This meeting 1) identified problems with overall childcare policies; 2) established and presented concepts of early childhood education and childcare for young children aged 0 to 8 ; and 3 ) adopted the view that the production of basic data for the establishment of scientific childcare policies was an urgent task.

This report identified the problems of unsatisfactory childcare support programs for each child's age group, and highlighted inefficiencies in existing childcare support projects, which were allocated segmentally to each ministry such as the Ministry of Education, the Ministry of Education and Human Resources Development, Ministry of Labor Affairs, and the Ministry of Agriculture and Forestry. In particular, this report identified the conflicts existing between the early childhood education and childcare sectors, as well as the inequity between the private and public systems. Accordingly, it systematically put forward a number of concepts of age-specific support policies, and also proposed the collection of raw data related to childcare, which was deemed necessary for reinforcing equality of support and the efficiency of policies.

\section{The National Survey of Childcare and Early Childhood Education $^{3}$}

According to the report on the First Phase of the National Childcare Support Policy, raw data collection for the establishment of scientific childcare policies was undertaken. Since this 2004 survey, the Government has been required to conduct a survey on the actual status of

Table 1

Major contents of the five projects on the national survey on the status of childcare and early-childhood education

\begin{tabular}{ll}
\hline \multicolumn{1}{c}{ Projects } & \multicolumn{1}{c}{ Contents } \\
\hline $\begin{array}{l}\text { Survey on users of childcare and } \\
\text { early childhood education services } \\
\text { and investigation on the actual } \\
\text { status. }\end{array}$ & $\begin{array}{l}\text { To identify the status of the use of childcare facilities (kindergartens, childcare } \\
\text { centers, private schools) and demand for such services. } \\
\text { To produce data based on the establishment of a plan on creating kindergartens } \\
\text { and childcare facilities for each region. }\end{array}$ \\
\hline $\begin{array}{l}\text { Survey on the status of childcare } \\
\text { facilities and survey on status of } \\
\text { kindergartens. }\end{array}$ & $\begin{array}{l}\text { To investigate childcare and early childhood education services as well as the } \\
\text { levels of quality. } \\
\text { To produce data to provide a basis for a scheme aimed at improving childcare } \\
\text { facilities and kindergartens. }\end{array}$ \\
\hline $\begin{array}{l}\text { Study on standard costs of } \\
\text { childcare and early childhood } \\
\text { education as well as a reasonable } \\
\text { level of support. }\end{array}$ & $\begin{array}{l}\text { To calculate expenses for childcare and early childhood education (standard } \\
\text { childcare costs). }\end{array}$ \\
\hline $\begin{array}{l}\text { To identify a reasonable level of support for the households concerned. } \\
\text { To collect data for a childcare expense support scheme. }\end{array}$ \\
$\begin{array}{l}\text { To present a scheme to increase the opportunities of using childcare facilities, } \\
\text { survey of childcare and education. }\end{array}$ & $\begin{array}{l}\text { reduce parental fees for childcare and early childhood education, and enhance } \\
\text { the quality of services. }\end{array}$ \\
\hline
\end{tabular}


the childcare every five years in accordance with the amendment of the relevant law ${ }^{4}$. The survey on childcare and early childhood education systems, conducted for the first time in 2004, was a comprehensive investigation on a national scale, and included interviews with 12,000 households and 6,700 young children throughout Korea and also targeted 8,246 kindergartens and 24,217 childcare facilities in operation at the time. This national survey consisted of five projects: the use of childcare and early-childhood education institutes and included an investigation into the actual status of the above; investigation of the status of childcare facilities; survey on the status of kindergartens; a study on the standard costs of childcare and early childhood education as well as a reasonable level of parental fees; and comprehensive reporting on the survey of childcare and early childhood education. The data that was collected became the basis for indicating the status of childcare and early childhood education systems in 2004. The details of the five projects are presented in Table 1.

\section{The Second Scheme of the National Childcare Support Policy $^{5}$}

The Second Scheme of the National Childcare Support Policy reported by the Presidential Committee on Aging and Future Society at the 60th Session of the National Agenda Meeting in May 2005 set directions for policy and outlined detailed support programs. Based on the basic metric data collected through the survey conducted in 2004, the national policy of the report specified the key objectives of a childcare policy and also presented a comprehensive childcare support scheme, including a financial support system.

In the second report, 'development of future human resources', 'expansion of women's participation in economic activities' and 'increasing the birth rate' were set as the visions of the childcare policy. In addition, a policy program was presented, which aimed at: 1) increasing access to childcare facilities and kindergartens, 2) easing the burden of childcare fees imposed on households, and 3) the quality of childcare services. The core tasks for three objectives were formulated as follows:

(1) Increasing access to childcare facilities and kindergarten

- Produce data on the additional demand for kindergartens and childcare facilities for each region and age group, and deploy these institutions in a balanced manner.

- Expand public childcare centers ${ }^{6}$ and coordinate their functions

(2) Easing the burden of childcare expenses imposed on households

- Project standard costs of childcare and early childhood education for the enhancement of quality of services

- Share an increased portion of expenses with the Government $^{7}$

- Expand support on childcare and education fees on an annual basis in a way which is graded according to family incomes

(3) Improving quality of childcare services

- Develop and provide a national level of qualitative early childhood education, standard childcare curriculum, and activity programs

- Implement accreditation of childcare facilities, conduct assessment of kindergartens, and connect the assessment results with financial support

In all, the directions of the First and Second Scheme of National Childcare Support Policies can be said to have characterized the direction of Korea's recent childcare support policy and also serves as an indicator for specific policy tasks. A conceptual framework for the two sessions of national childcare policies is presented in Figure 2.

\section{Announcement of a Mid-and-Long Term Childcare Plan by the Ministry of Gender Equality and Family}

In the Second Scheme of National Childcare Support Policy by the Presidential Committee on Aging and Future Society in 2005, there was a proposal on the implementation of the five-year plan of childcare policy 


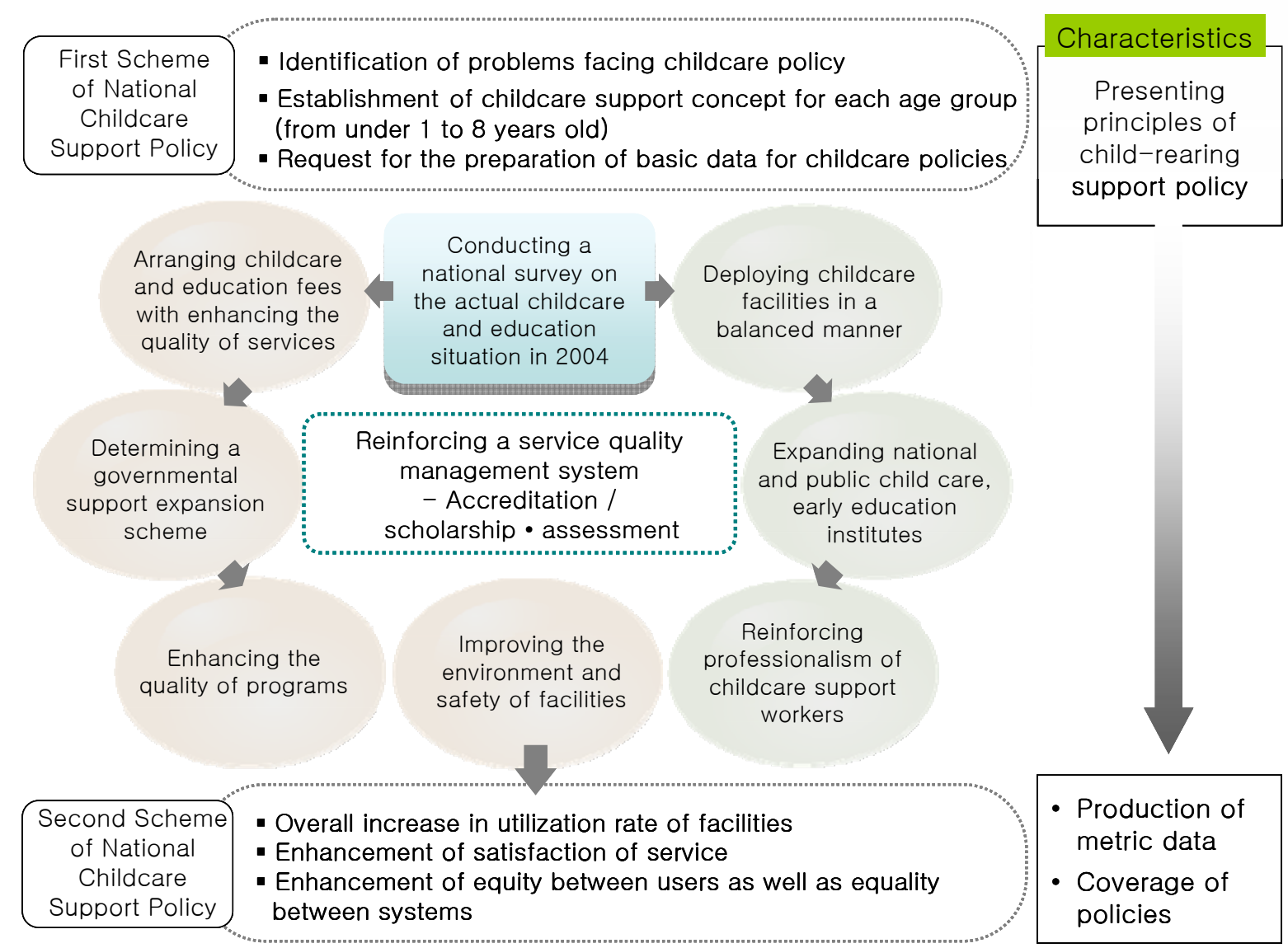

Figure 2. Conceptual framework of the First and Second Scheme of National Childcare Support Policies

following its announcement. This plan was provisionally named the "Saessak Plan", which means sprout plan, by the Ministry of Gender Equality and Family and the Ministry of Education and Human Resources Development. Accordingly, in 2006 the Ministry of Gender Equality, which was responsible for Korea's childcare policy, unveiled the first phase of a mid-term childcare plan for 2006 to 2010, known as the "Saessak Plan". According to the plan, the objectives of the policy were to reinforce the publicity of childcare and provide high quality childcare services. This plan was well known not only to childcare specialists but also to the members of the general public since several public hearings were held in Korea after the five tasks had been first presented. The background of the establishment of the plan was the national childcare support policies proposed in 2004 and
2005, and the direction of core policies and contents of the plan were not improvised, but they were, in principle, based on the first and second scheme of the national childcare support policies reported over the two years, and thus were both consistent and systematic in nature and design.

Korea's recent childcare policy is changing, and at least some of this criticism is related to the perception that it is changing too rapidly. These rapid changes can be seen through fact that the policies are frequently changing, particularly through the implementation of policy requiring responsibility following the expansion of support for childcare facilities. There is a perception that the policy is drastically changing in the process of actualizing the efforts in the short term to expand childcare support. Since 2003, the Korean Government 
has increased the budget for childcare support in a consistent manner, and has undertaken policy projects which require a high level of governmental intervention in order to expand the equity of support and responsibility.

\section{Status of Korea's Childcare Policy as Measured by the Major Policy Indicators}

As discussed above, the childcare support projects undertaken by the Korean Government over the past four years are 1) the enhancement of the access to childcare facilities, 2) the alleviation of household burden incurred from childcare service expenses, and 3) the reinforcement of quality of childcare service. These three projects are childcare policy tasks pursued not only by Korea, but also commonly pursued by other nations which require childcare support policies. This paper will briefly outline projects focused on by the Government in order to accomplish these three tasks, and also examine whether these projects are bringing about the expected results, and improving or worsening childcare conditions, making use of all relevant and available data.

Policy for Enhancing Accessibility to the Childcare Facilities and Kindergartens
The policy aimed at enhancing access to childcare services aims primarily at increasing the actual supply of childcare. In particular, it aims to establish childcare centers near the child's area of residence at appropriate levels. Korea implemented an intensive policy to expand childcare facilities over the three years from 1995 to 1997. During this period, a great number of private run centers were established, resulting in the current sufficiency of childcare facilities. However, there exist additional demands on such centers according to regions, and, in particular, there is additional demand on care for infants below the age of 3 years ${ }^{8}$. Therefore, at this point in time, the most urgent policy requirement is to expand public childcare facilities which are preferred by parents in terms of service quality and cost. Currently, about 75 percent out of all children using childcare facilities and kindergartens attend private institutions.

\section{The supply of childcare facilities and kindergartens:}

Over the most recent five years, the supply of childcare facilities has grown. Specifically, the number of childcare facilities increased from 22,147 in 2002 to 29,233 in 2006, and the number of kindergartens decreased by 53, from 8,343 in 2002 to 8,290 in 2006. The decline in the number of kindergartens can be interpreted as a result of the increase in childcare

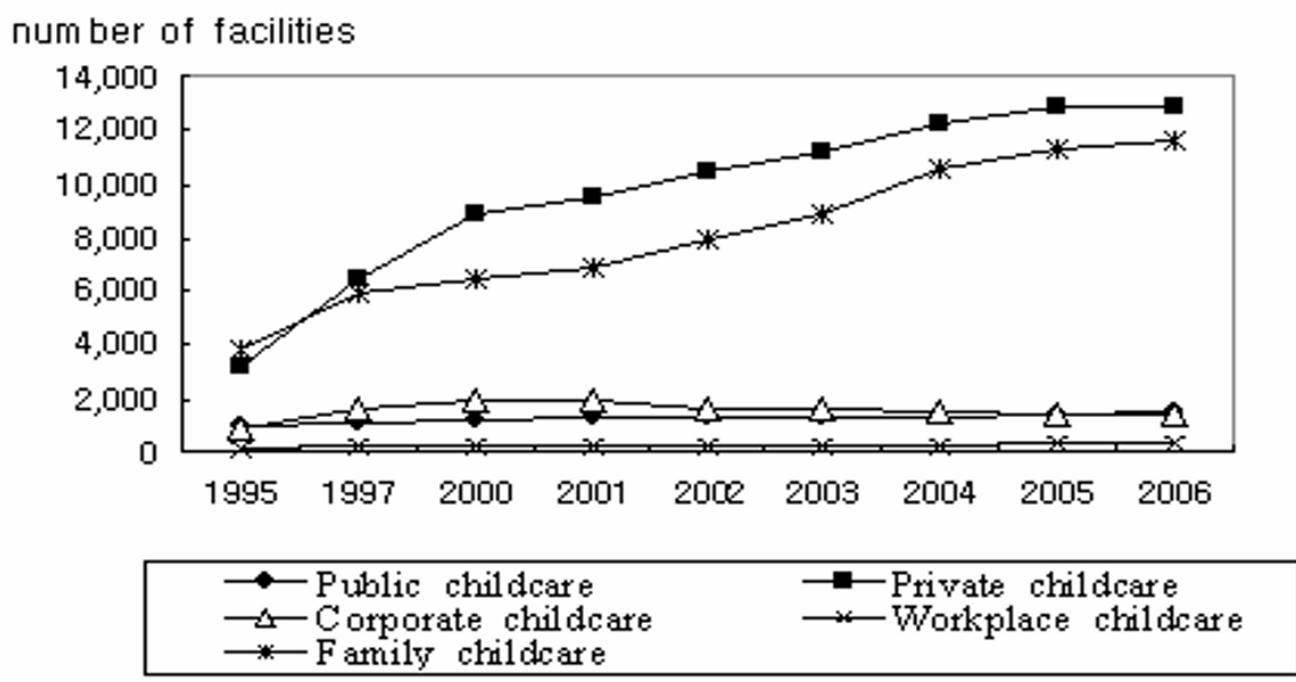

Figure 3. Changes in the distribution ratio in the establishment of childcare facilities by types of founders from 1995 to 2006 
facilities and a reduction in the population of 3 to 5 year olds.

The ratio of public childcare facilities to kindergartens: Examining the distribution of childcare centers according to the types of founders of the facilities, national and public centers are in further decline compared with private sector facilities. The proportion of national and public institutions dropped from 6.0 percent in 2002 to 5.6 percent in $2006^{9}$. The project for the expansion of national and public childcare facilities, focused on by the Government with an aim to increase the access to such systems, has failed to have the desired effects.

In terms of kindergartens, the proportion of private kindergartens decreased somewhat, while public kindergartens increased by 220 over the past five years, private kindergartens decreased by 273 over the same period.

Table 2

Changes of the number of type-specific kindergartens

\begin{tabular}{ccccc}
\hline Year & National & Public & Private & Total \\
\hline 2002 & 3 & 4,237 & 4,103 & 8,343 \\
\hline 2003 & 3 & 4,281 & 4,008 & 8,292 \\
\hline 2004 & 3 & 4,325 & 3,918 & 8,246 \\
\hline 2005 & 3 & 4,409 & 3,863 & 8,275 \\
\hline 2006 & 3 & 4,457 & 3,830 & 8,290 \\
\hline
\end{tabular}

The number of children enrolled in childcare facilities and kindergartens: The change of the utilization rate of childcare systems is an important indicator which is closely correlated with the accessibility of such centers. According to this indicator, the users of such facilities increased by 190,000, from $1,350,000$ in 2002 to $1,540,000$ in 2006. This increase in the number of child users holds many implications. Above all, it means that, in Korea, child daycare centers and kindergartens have been evolving into general childcare and early childhood education facilities. The fact that infants and preschool children using such institutions increased can be a positive indicator in that more infants and preschool children are benefiting from childcare and education programs.

Table 3

Number of children enrolled in childcare facilities and kindergarten for each year

\begin{tabular}{cccc}
\hline Year & $\begin{array}{c}\text { Total of } \\
\text { infants and } \\
\text { preschool } \\
\text { children }\end{array}$ & $\begin{array}{c}\text { Number of } \\
\text { childcare } \\
\text { center users }\end{array}$ & $\begin{array}{c}\text { Number of } \\
\text { Kindergarten } \\
\text { users }\end{array}$ \\
\hline 2002 & $3,720,013$ & 800,991 & 550,256 \\
\hline 2003 & $3,598,194$ & 858,345 & 546,531 \\
\hline 2004 & $3,497,255$ & 891,028 & 541,713 \\
\hline 2005 & $3,158,538$ & 941,388 & 541,603 \\
\hline 2006 & $3,011,800$ & 990,069 & 545,812 \\
\hline
\end{tabular}

\section{Policies for Alleviating the Burden of Early Childhood} Education and Childcare Fees

Governmental policies for alleviating childcare costs include: an increase in the childcare budget; the introduction of childcare support provided according to the different income levels of families; and the provision of basic subsidies covered by the government as an increased proportion of childcare costs.

The childcare support budget: Out of the total governmental budget areas over the past four years, the childcare support budget has increased the most out. The childcare budget soared by an annual average of 43.6 percent, from KRW 479 billion in 2002 to KRW 2 trillion and KRW 38 billion in 2006. The early childhood education budget grew annually by 27.5 percent from KRW 334.7 billion in 2002 to KRW 886 billion in 2006. In particular, additions to the budget have been recently introduced by the Government in order to support young children from farming households since 2004, resulting 
in the huge quantitative expansion of the overall childcare budget..

The ratio of childcare support budget to GDP: The level of national childcare and early childhood education support is assessed according to the ratio of childcare budget to the GDP of the country. Korea still shows a relatively low level of early childhood education support, well short of reaching the average of 0.5 recorded by the OECD in 2004.

Compared to four years ago, the ratio of the childcare budget against GDP was 0.24 percent, and the budget of early childhood education rose to 0.10 percent as of 2006. The total ECEC (Early Childhood Education and Care) support budget against GDP grew from 0.12 percent in 2002 to $0.349^{10}$ percent in 2006; this represents nearly a three-fold increase. The level of the entire ECEC support budget still remains unsatisfactory. However, the ratio of ECEC support budget to GDP is growing due to an increase in the annual childcare budget.

\section{Graded support for childcare and early childhood} education fees according to household income levels: Korea introduced a support system for graded childcare and early childhood education fees in 2004. Prior to 2004, childcare support was only provided to low income families, as stipulated by law. The Government has continuously increased the number of children provided with graded childcare and early childhood education fees, and has raised support funds since 2004 .

Looking at the changes in the number of young children who are provided with childcare support for example, in 2002 such support was granted to 106,000 infants and preschool children belonging to lower income groups. As of 2007, the number will increase over five -fold, since approximately 563,000 children, belonging to the average income group, consisting overwhelmingly of urban workers, will also be provided with graded childcare fee support.

Basic subsidy support: The basic subsidy support system generally provides some portion of childcare

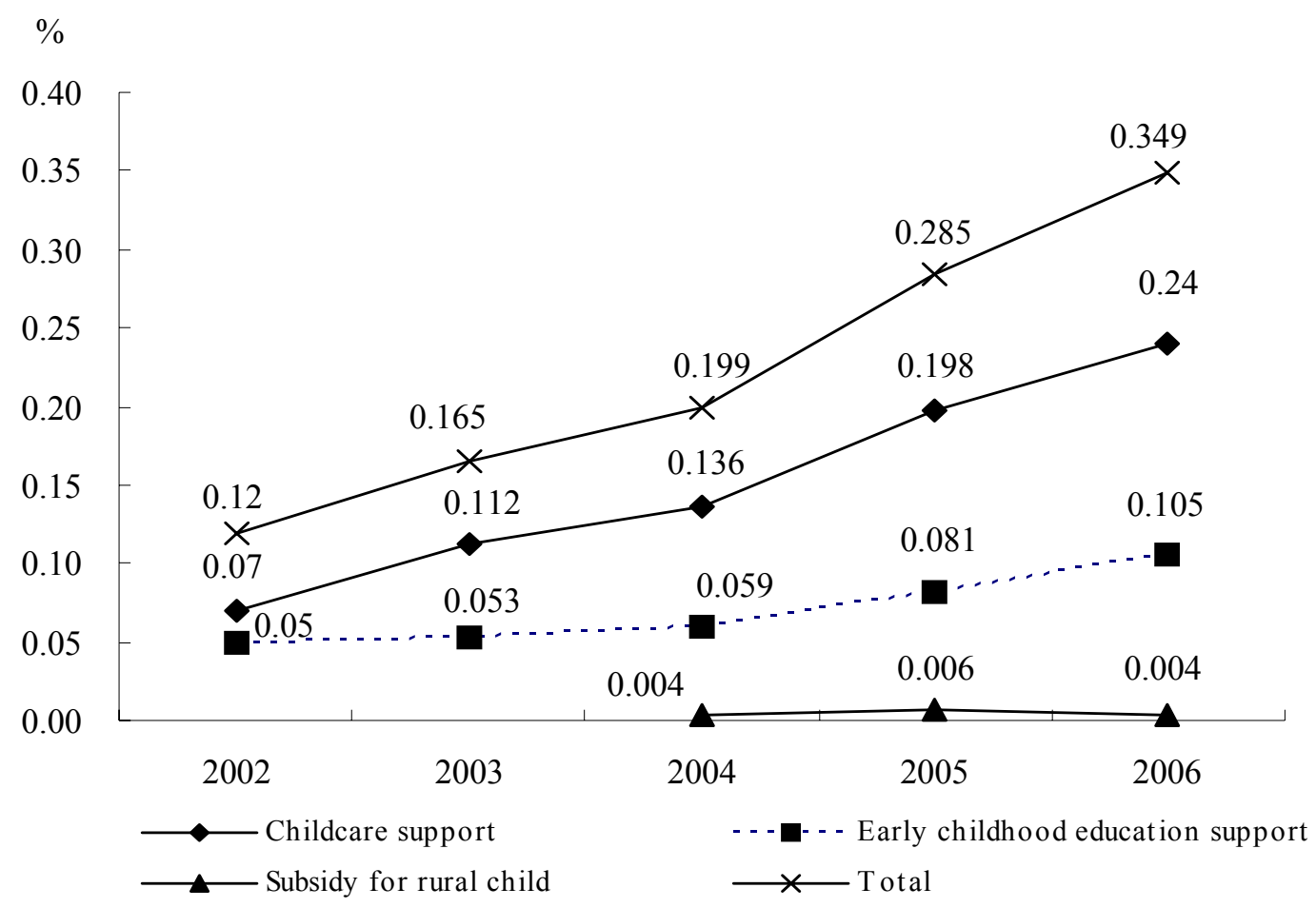

Figure 4. Ratio of childcare and early childhood education budget to GDP 


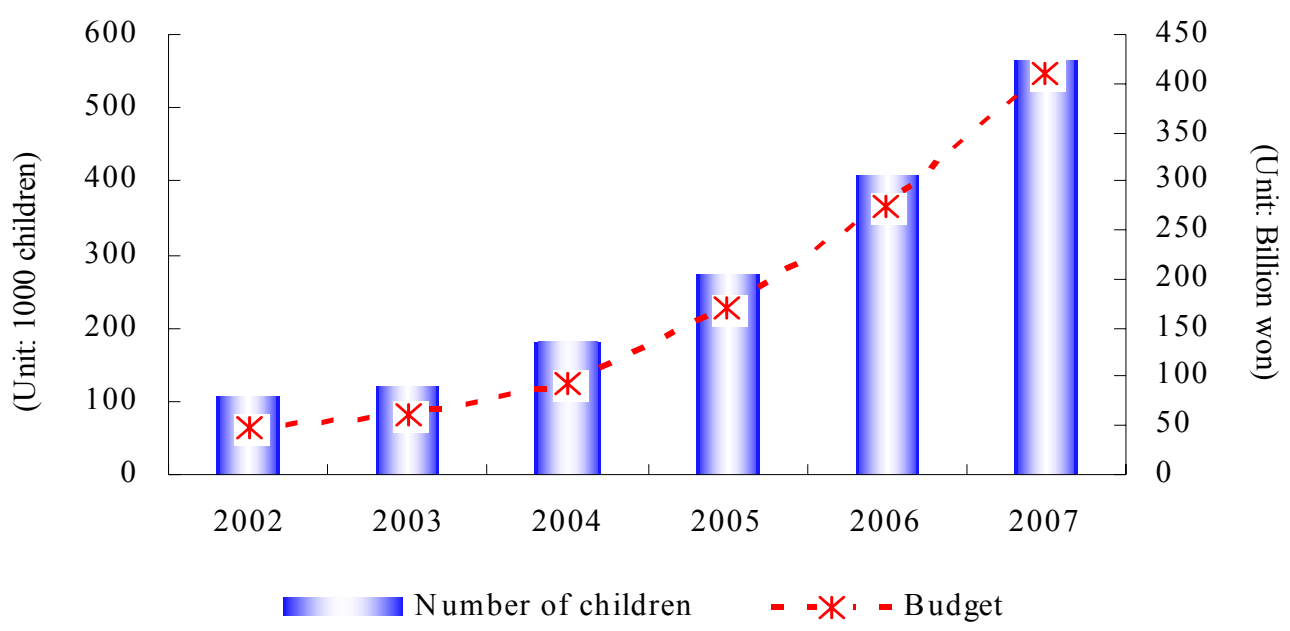

Figure 5. Number of graded-fee supported children and trend of support budget

expense for young children who go to a private childcare facility and a kindergarten. This basic subsidy support has been provided for infants aged up to 2 years.

This system of basic subsidy support has been provided by the Government to cover additional childcare expenses incurred by enhancing the quality of private childcare service ${ }^{11}$. This began with the support for infant care, as one of the core policy tasks of the Second Scheme of National Childcare Support Policy established by the Presidential Committee on the Ageing and Future Society in May 2005.

The basic subsidy support system for private childcare was proposed in order to raise the quality of private childcare service, and aims to gradually standardize childcare fees by 2010, which were applied differently to users of the private and public systems. Through these efforts, it was hoped, that the system would to lead to greater equity between users of public and private childcare facilities, as well as fair competition between operators in the public and private sectors.

The basic subsidy support system for infant care at private systems has been in operation since 2006 , and is therefore now well established in the field of infant care. However, whether the basic subsidy for 3 to 5 year olds in the private sector will be provided or not will be decided after an assessment is conducted on the effects of a trial operation in place, which focuses on three areas in Korea: enhanced service, reduced childcare and kindergarten education fees, and improved conditions for and treatment of teachers.

\section{Policy for Improving the Quality of Childcare and Early Childhood Education}

The projects which the Korean Government has recently focused on with an aim to improve the quality of childcare services are: to initiate a quality accreditation system for childcare facilities as well as an evaluation system for kindergartens, to improve the physical environment of facilities, to improve the working conditions for staff at childcare facilities and kindergartens, and to improve the quality of the curriculum for childcare and early childhood education.

\section{Accreditation of childcare facilities and evaluation}

of kindergartens: In Korea, an accreditation system for childcare facilities was initiated as a trial operation in 2005. The implementation, both in manner and form, of this system has been specified through policy studies since 2003, and has been the focal point of several public hearings. In addition, the legal basis for a state-led 
Table 4

Age-specific basic subsidies and the number of supported young children

\begin{tabular}{ccccc}
\hline Classification & Under 1 year & 1 year & 2 years & Number of supported children \\
\hline Year 2006 & KRW 249,000 & KRW 104,000 & KRW 69,000 & 191,000 \\
\hline Year 2007 & KRW 292,000 & KRW 134,000 & KRW 86,000 & 200,000 \\
\hline
\end{tabular}

Note. In 2007, the unit price for childcare borne by parents is KRW 361,000 for under 1-year olds, and KRW 262,000 for 2-year olds

quality accreditation system was incorporated into the amended Child Care Act and the operation of the system itself has unfolded over the three years since its inception.

In Korea, where most of the childcare facilities are under private management, the Government encourages childcare facilities to voluntarily participate in the accreditation process and grants an accreditation certificate. An individual childcare center applies for quality accreditation on a voluntary basis, and conducts a self-evaluation of five to seven categories, consisting of 60 to 80 items selected by the Government, followed by the reporting of the results. Trained experts then visit the center and conduct an assessment. Through expert consultation on the self-evaluation and the on-the-spot assessment, a final decision is made whether the center will be accredited or not. Since its initiation as a trial operation in 2005, 3,300 childcare facilities have been accredited, as of August 2007. Taking into account the total number of 29,000 facilities throughout Korea, the number of accredited childcare facilities is relatively small, but it is expected that this figure will increase.

Based on the Early Childhood Education Act enacted in 2004, the Government will soon conduct evaluations on kindergartens. After the completion of a pilot research scheme in 2007, kindergarten evaluations ${ }^{12}$ will begin in 2008 on a nation-wide basis.

In order to motivate childcare facilities and kindergartens to participate in the accreditation and evaluation process, the Government began to seek ways to connect the assessment results with the basic subsidy system and the salaries of teaching staff. Through a strengthened scheme for linking support with evaluation, this policy has been construed as an effort to enhance the public transparency of the private sector.

The reinforcement of the safety conditions of facilities: The Korean Government has increased the budget allocation twenty-fold in order to improve the physical environment of childcare facilities over the last five years. Not only through increasing the budget allocation, but also by amending the relevant laws, the Government has made an effort to improve conditions with a view to creating safer environments. The locations of centers and standards for indoor and outdoor equipment have all been reinforced for the safety of infants and preschool children. The Government requires individual centers to include the establishment of safety-related emergency facilities in case of accidents or disasters. Since accidents still occur despite the reinforcement of regulations, and parents generally are not satisfied with the safety levels of facilities.

Improvement in teachers' working conditions: In order to improve the payments for staff at private childcare centers, and thereby bringing them in line with the level of payments for teachers at national and public facilities, the Government has recently explored the idea of connecting the accreditation system with teachers' salaries, as well as using a certain proportion of basic subsidies for payments to teachers. With regards to kindergartens, the Government has paid head teacher allowances to 2,000 teachers working at private kindergartens in rural areas with poor working conditions since 2006 in order to improve the conditions for teachers. Furthermore, the Government plans to pay such allowances to 11,300 teachers in 2007 and to expand this to 23,000 teachers in cities. As illustrated in a saying that 
'the quality of childcare and early childhood education services can not be beyond the level of teachers', it is very important to improve the working conditions of teachers in order to improve the quality of childcare and early childhood education so that teachers with high skill and experience levels will be able to continue to work. Although the Korean Government is expanding the support necessary for the improvement of working conditions, it still remains fundamentally unsatisfactory. A high turnover rate and low salaries of childcare staff persist as long-standing, serious problems in the field of early childhood education and care.

The development of a national level of curricula for general childcare and early childhood education: One of the most important elements determining the quality of childcare service is the quality of the activities that young children are actually experiencing. From this perspective, the Government has focused on developing and distributing standard childcare curricula on a national level, based on the Child Care Law over the past few years in a bid to provide experiences appropriate for the development of children up to 5-years old. Educational curricula for kindergarten children aged 3 to 5 have been provided, which allow children to experience holistic education appropriate for their development. Currently, the 7 th edition of the national kindergarten curriculum is underway.

\section{Major Issues in the Undertaking of Korea's Childcare Policy}

This paper has outlined the policy directions and major projects undertaken in a positive way, which are considered to be meaningful childcare and early childhood education policies. However, the assessment on the part of the general public on childcare policy is not as positive. Despite the high childcare expenses incurred by the general public, parents are not fully satisfied with the quality of service they receive. The inequity between the private and public sectors remains as a poignant focus of social conflict. Some are skeptical as to the effects of the four-fold increase in the childcare support budget over the past four years. This sentiment stems from a lack of trust in transparency in supporting and operating childcare centers and kindergartens.

Due to reinforced regulations over the past few years, the operators of childcare facilities have criticized the Government for excessive intervention. Those who consider requirements and conditions upon which financial support by the Government is dependent, oppose such conditions due to their strictness, while at the same time, demanding greater liberalization. Likewise, the problems concerning childcare policies are seen differently according to various perspectives: whether those perspectives are those of the users or providers, policy makers or the public. Accordingly, discussion continues, even on childcare support to address each problem.

The expansion of public institutions vs. the utilization of private institutions

Experts and civil right activists claim that the expansion of the accessibility of public childcare centers which ensure a basic level of quality, to some extent, will contribute to raising childcare service quality, stabilize service costs, and enhance the publicity of childcare and early childhood education. On the contrary, there are some suggestions that a more realistic policy would be to take full advantage of the existing private facilities in operation. This would mean that a policy for raising the quality level of the private sector will be more effective in reality in cases where it would otherwise be difficult to secure funds for establishing public centers.

\section{Support for low-income families vs. general support}

Some insist that a policy based on a selective welfare ideology which restricts the support for childcare and early childhood education expenses to low-income groups is necessary. Such a claim is made by some policy makers from Korea's economic ministries, as well 
as economy-related groups of experts. This view contrasts with other claims that the externality of childcare support and the degree of social urgency involved make a general support policy necessary. As an example which illustrates this phenomenon clearly, opinions on the current issue of basic subsidy support are divided.

\section{Control vs. self-regulation of childcare fees}

There is a claim that the self-regulation of childcare fees will contribute to the enhancement of childcare service through competition in service, with the view that regulations on prices cause poor quality childcare service. Furthermore, since options for consumers will be expanded according to a wide range of service price options, the market for childcare will be revitalized, even contributing to the support of high-income groups. However, the adoption of a self-regulating price mechanism means that the Government will have to surrender the public nature of childcare, because the service provided for young children will be graded according to the incomes of their parents, resulting in deepening socio-economic polarization. In terms of private childcare, there is a degree of opposition to self-regulation because price competition rather than service competition is likely to cause those facilities in poor condition to be neglected.

\section{Support for facilities vs. for young children}

The Korean Government has provided a proportion of labor costs for public institutions as well as corporate facilities, together with support for childcare expenses graded according to incomes for young children regardless of the institutions that they attend. There is disagreement over whether funds for childcare should be directly provided to the consumers, young children, or whether funds should be provided to support facilities (including labor costs). Currently, the majority of service providers favor the funding of labor costs. On the other hand, the majority of the public and users prefer direct support for young children.
In 2005, the Government reduced the level of support for institutions (labor costs) and instead increased support for children. There are many experts who propose the expansion of support for young children in order to enhance the transparency of financial support and thereby raise the perception of governmental support for users. However, since a stabilized operation of institutes is significantly correlated to the quality of service, the expansion of the level of support for facilities is also a persuasive opinion.

\section{Maximization vs. minimization of governmental intervention}

Recently, the Government reinforced specific regulations related to the operation and safety conditions of childcare service centers, and has implemented an electronic administration system for the transparency of financial support. Responding to these governmental activities, some service providers are demanding that the Government minimize levels of governmental intervention. Some insist that the governmental policy for childcare should move towards a self-regulated management system, in line with the overall national policy, which is to eliminate unnecessary regulations and rules. On the other hand, others argue that, at this point, it is more important to maintain control over safety requirements and the quality of service at the governmental level in order to prevent moral hazards in the field. They insist that the administrative authorities should be strengthened in order to achieve the transparent management of the greatly expanded financial support provided by the Government.

\section{Conclusion}

This paper has outlined the background into establishing the directions of recent childcare and early childhood education policies in Korea, identified the major childcare policy projects, and analyzed a wide range of issues in undertaking these policies. In 
conclusion, Korea's childcare policies are evolving from a conservative approach to a more progressive one. Despite the diversity of opinion within Korean society in terms of welfare and ideological debates of the nation, policies and perspectives regarding all aspects of on childcare are expected to continue to become increasingly progressive. This is because financial support for childcare has been dramatically increased on an annual basis, and, moreover, the national consensus has seen a broadening of governmental support for childcare due to the crisis of an ever lowering fertility rate.

Even to satisfy expectations and demands for the financial expansion of childcare support, there is an urgent need for studies analyzing precisely which support policies will enhance accessibility and quality of childcare services and which will bring about the desired effects and achieve the goal of being cost effective and providing value for money. Furthermore, further study is needed on what policy direction will make the greatest contribution to realizing the ultimate goals of a childcare policy, which are to develop future human resources, support women's participation in economic activities, and raise the fertility rate. This work is a difficult undertaking because it requires scientific data as well as drawing a consensus from the parties concerned of the interest of childcare support. The work should be based on a clear understanding of the reality of childcare.

Not only experts in the field of childcare services and policy makers, but also the general public who are outside of childcare policy, have a strong interest in childcare policies as the budget of childcare support increases. Such interest has already been expressed through differences in opinions on childcare support schemes, and moreover, has emerged as a major issue in the undertaking of policy projects. Abstract claims which continue to insist on the universality and equity of childcare will not be persuasive without hard evidence and should be reinforced with such evidence if they are to succeed. Scientific data is necessary to justify the grounds for the expansion of childcare support. Consistent and intensive monitoring of childcare policy programs is also required by experts in order to check the effectiveness and efficacy of such schemes, as well as providing a valuable basis of accumulated scientific data for effective future childcare policies.

\section{References}

Choi, E. (2005). Low fertility and policy challenges in Korea. Paper presented at the International Conference on Low Fertility and in Effectiveness of policy Measures in OECD, Korea Institute for Health and Social Affairs, Korea.

Joint Team of Relevant Ministries. (2006). Saromajee plan 2010 for aging society. Seoul, Korea: Ministry of Gender Equality.

Ministry of Gender Equality. (2005). A study on the standard expenses and reasonable level of support for childcare and early childhood education. Seoul, Korea: Ministry of Gender Equality.

Ministry of Gender Equality. (2005). Comprehensive report on the survey of childcare and early childhood education conditions. Seoul, Korea: Ministry of Gender Equality.

Ministry of Gender Equality. (2005). Report on the survey of childcare facilities. Seoul, Korea: Ministry of Gender Equality.

Ministry of Gender Equality. (2005). Report on the survey of kindergartens. Seoul, Korea: Ministry of Gender Equality.

Ministry of Gender Equality and Family. (2006). Mid-and long-term child care plan for 2006 to 2010. Seoul, Korea: Ministry of Gender Equality and Family.

OECD (2006). Education at a glance OECD indicators 2006. Paris: OECD publications.

Presidential Committee on Aging and Future Society. (2004). First Scheme of National Child Support Policy. Seoul, Korea.

Presidential Committee on Aging and Future Society. (2005). First Scheme of National Child Support Policy. Seoul, Korea.

You, H. (2007). Childcare support policy 2002-2006. 
Unpublished manuscript, Korea Institute for Child Care and Education. Seoul, Korea.

\section{Note}

1. Choi, Eunyoung (2005). Low fertility and policy challenges in Korea. A Paper Presented at the International Conference on Low Fertility and in Effectiveness of Policy Measures in the OECD. Korea Institute for Health and Social Affairs.

2 Korea recorded the lowest level of Total Fertility Rate (TFR) among the OECD nations with 1.07 in $1985,1.47$ in 2000, and 1.08 in 2005. In 2006, Korea's TFR recorded 1.13, showing a small increase over the previous year.

3 A survey on the actual status of childcare and early childhood education conducted by four state-run research institutes in 2004, which was complied into five volumes and reported in 2005.

4 A provision mandating the Government to conduct a survey on the actual childcare conditions throughout Korea was stipulated in the Child Care Law amended in 2004.

5 Reporting on the second National Policy of Childcare Support was not open to the public, and thus the information was not circulated.

6 Through the conclusion of the Agreement of a "Joint Meeting on Measures for Low Fertility Rate and Aging" in 2006, the Government and civil society reached consent on this plan from which a Task Force for the Establishment of National and Public Childcare Facilities was organized and has since operated.

7 In the report on the Second Scheme of National Childcare Support Policy, this was called the "Expenditure for Enhancement of the Quality" in the childcare service. Later, it was changed to "Basic Subsidy" for infant care in the private system, and "Basic Subsidy" for preschool children, which is currently underway as a trial operation for private childcare system users.

8 According to the results of the basic survey on childcare and early childhood education conducted in 2005 , there were additional demands on 4,510 small and medium childcare centers and 785 kindergartens nationwide. Among these, the additional demands on centers with a capacity of 30 infants totaled 3950, preschooler centers with a capacity of 60 totaled 560, and kindergartens with a capacity of 60 totaled 785 (Report on the Second Phase of National Childcare Support Policy).

9 The number of national and public childcare institutes increased from 1,330 in 2002 to 1,943 in 2006; other types of facilities except for national and public centers grew from 20,817 to 27,590 over the four years, indicating the portion of national and public centers decreased.

10 GNP of Korea in 2006 recorded KRW 847 trillion and 876 billion (According to the Bank of Korea)

11 This system calculates the difference between the standard childcare expenses (standard early childhood education expenses) in Project 4 in the basic survey made in 2004 and current childcare expenses which are not covered by parents but by the Government. This standard childcare cost is calculated to be almost equivalent to the childcare cost per capita in the national and public systems, which are supported with labor costs.

12 Currently, the Korea Institute of Child Care and Education, requested by the Ministry of Education and Human Resources Development, is developing and conducting research on categories for kindergarten evaluation manuals, and the Government plans to implement an evaluation project as a trial operation in second half of 2007. 